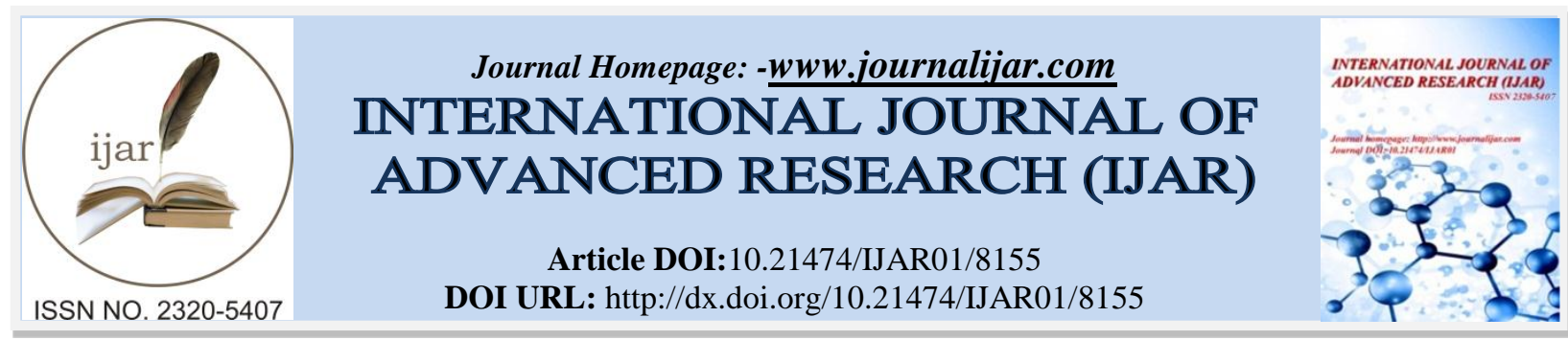

RESEARCH ARTICLE

\title{
A COMPARATIVE STUDY OF BLEACHING WITH HYDROGEN PEROXIDE VERSUS CARBAMIDE PEROXIDE ON ENAMEL SURFACE AND THE EFFECT OF AMORPHOUS CALCIUM PHOSPHATE APPLICATION FOLLOWING BLEACHING (SCANNING ELECTRON MICROSCOPE ATTACHED WITH ENERGY DISPERSIVE X-RAY ANALYZER STUDY).
}

\author{
Rehame M. Ameen ${ }^{1}$, Rania A. Awwad² and Ethar S. Mohamed ${ }^{3}$. \\ 1. Professor of Oral Biology, Faculty of Dentistry, Ain Shams University, Egypt. \\ 2. Lecturer of Oral Biology, Faculty of Dentistry, Ain Shams University, Egypt. \\ 3. Assistant Lecturer of Oral Biology, Faculty of Dentistry, Future University, Egypt.
}

\section{Manuscript Info}

\section{Manuscript History}

Received: 04 October 2018

Final Accepted: 06 November 2018

Published: December 2018

\section{Keywords:}

Hydrogen peroxide,Carbamide peroxide ,ACP,Enamel,SEM-EDAX.

\section{Abstract}

Bleaching agents have effect on chemical and morphological structure of enamel that must be taken into account when this therapy is used.

Aim: reveal and compare the effect of two bleaching agents containing a high a concentration of hydrogen peroxide (HP) and carbamide peroxide $(\mathrm{CP})$ on enamel surface and evaluate the re-mineralizing effect of amorphous calcium phosphate gel (ACP) on enamel surface.

Material and method: 32 extracted human upper first premolars were divided into 4 Control groups (CG) (before bleaching procedure), was named as: CG I, CG II, CG III and CG IV. 4 Experimental groups (EG) in which the teeth of the control groups utilized as experimental after bleaching procedure. Teeth were subjected to 40\% HP in EGI, 35\% CP bleaching in EGII, $40 \%$ HP \& ACP in EGIII and $35 \%$ CP \& ACP in EGIV. All groups were prepared to SEM analysis and EDAX.

Results: Both HP and CP significantly altered enamel superficial surface structure causing irregular surface, erosive lesions and craters. Globular precipitates covering the entire enamel surface and occlusion of enamel rod ends were detected following ACP application.The chemical profile results revealed decrease in $\mathrm{Ca}$ and $\mathrm{P}$ contents of enamel surface following bleaching, while they increased after application of ACP and the opposite was to the carbon content.

Conclusion: Hydrogen peroxide and carbamide peroxide have an erosive effect on enamel surface while ACP has a re-mineralizing effect.

Copy Right, IJAR, 2018,. All rights reserved.

\section{Introduction:-}

Tooth bleaching refers to a technique where chemical materials are applied to whiten discolored teeth. Bleaching materials contain a strong oxidizing agent that have the ability to preserve lighter colored teeth due to oxidation reactions (Attin et al, 2005). The population's increasing interest in whitening their teeth has motivated many manufacturers to develop products for use either in the dental office or at home (Sturdevant et al, 2006). The successful outcome of any of

Corresponding Author:-Rania A. Awwad

Address:-Lecturer of Oral Biology, Faculty of Dentistry, Ain Shams University, Egypt. 
the applied procedures depends on the etiology, diagnosis, and proper selection of bleaching materials and the correct clinical technique (Watts and Addy, 2001).

The methods of management of discolored teeth including removal of surface stain, bleaching techniques, and operative intervention to mask the underlying discoloration, as veneers and crowns (Sulieman, 2004). The improved bleaching materials and techniques have made dental whitening the most popular procedure because it is safe, simple, effective and minimally invasive when compared with other restorative treatments (Dietschi et al, 2010; Kim et al, 2011).

The external bleaching of vital teeth is based on the direct use of either hydrogen peroxide or carbamide peroxide (Maryline and Rene, 2008).Hydrogen peroxide (HP) is an oxidizing agent that produces free radicals. Dark-colored, long-chained, chromophore molecules are attacked by free radicals and split into less colored, smaller and more diffusible molecules Olta and Gurgan (2000). HP passes freely through the inter-prismatic spaces due to its lower molecular weight resulting in pigments oxidation (Minoux and Serfaty, 2008).Carbamide peroxide (CP) is the most commonly used agent in home bleaching technique. Many studies reported safety of $\mathrm{CP}$ as bleaching material Moraes (2006). Carbamide peroxide (CP) produces urea that break down to carbon dioxide and ammonia helping the maintenance of an alkaline $\mathrm{pH}$, which potentiates the bleaching agent action (Budavaria et al, 1989; Sun, 2000). Urea enhances anti-cariogenic effects, saliva stimulation and wound healing (Archambault, 1990).

Amorphous Calcium Phosphate (ACP) was described first in the mid-1960s by Aaron S. Posner (Boskey, 1997). An amorphous precipitate was derived by accident when mixing high concentrations of calcium chloride and sodium acid phosphate in buffer (Eanes et al, 1965). ACP is an inorganic amorphous calcium phosphate made by combining soluble salts of calcium and phosphorous. It works via a unique method that uses amorphous calcium phosphate compounds in a carbonate solution to crystallize and form hydroxyapatite. These crystals then fill in microscopic surface defects and repair early carious lesions, as well as make teeth smoother, stronger and less sensitive. ACP also reduces the precipitation of surface protein which limit the chromogens potential to bind to teeth (Gray et al, 2007).

The aim of the present study was to compare the effect of hydrogen peroxide (in-office bleaching) and carbamide peroxide (home bleaching) on human surface enamel and the effect of amorphous calcium phosphate (ACP) as a remineralizing agent following bleaching.

\section{Materials and methods:-}

Thirty two sound upper first premolars freshly extracted for orthodontic reason were used in the present study. The extracted teeth were washed thoroughly under running water and then they were examined under stereomicroscope to exclude teeth with cracks, calculus, abrasions and decay on the buccal surfaces (Arnold and Gaengler, 2012).

Wax will be placed on the middle third of the buccal surface of all the teeth. Acid resistant nail varnish will be coated in 2 layers on the buccal surface all around the wax. Then the wax will be removed to expose the isolated middle third of enamel surface (Sathe et al, 2014). Before application of the bleaching agents, teeth will be removed from distilled water and the enamel surfaces will be blotted to be dried.

Teeth were then divided into 4 equal groups, each is eight teeth. Each group was used as a control and the same groups were re-used as experimental groups.

\section{Control groups: (before bleaching)}

These groups contained were divided into 4 equal groups ( 8 teeth each) as follows:

Control group I (CI group), Control group II (CII group), Control group III (CIII group) and Control group IV (CIV group).

\section{Experimental groups: (after bleaching)}

Control groups teeth were bleached to be used as experimental and were named as follows: Experimental group I (EI group), Experimental group II (EII group), Experimental group III (EIII group) and Experimental group IV (EIV group).

Experimental group I (EI ): (HP) 
Eight teeth were treated with $40 \%$ hydrogen peroxide gel (chemically activated) for 40 minutes (with two 20 minutes applications each, according to manufacturer instructions) then, teeth were stored in artificial saliva for 48 hours (Horning et al, 2013).

Experimental group II (EII ): (CP)

Eight teeth were treated with $35 \%$ carbamide peroxide gel for thirty minutes (according to manufacturer instructions) and then were stored in artificial saliva for 48 hours (Horning et al, 2013).

\section{Experimental group III (EIII): (HP and ACP)}

Eight were treated with $40 \%$ hydrogen peroxide gel (chemically activated) for 40 minutes (with two 20 minutes applications each, according to manufacturer instructions) followed by ACP application for 30 minutes (according to manufacturer instructions), then teeth were stored in artificial saliva for 48 hours.

\section{Experimental group IV (EIV ): (CP and ACP)}

Eight teeth were treated with $35 \%$ carbamide peroxide gel for thirty minutes followed by ACP application for 30 minutes (according to manufacturer instructions), then teeth were stored in artificial saliva for 48 hours.

Each tooth was washed under running water and the enamel surfaces was blotted to be dried. Then it was mounted on the SEM holderusing removable adhesive. The middle third ofenamel on buccal surface was adjusted to be examined and to measure the surface $(\mathrm{Ca})$ and $(\mathrm{P})$ weight \% using FEI/Inspect $(\mathrm{S})$ scanning electron microscope attached with energy dispersive Xray analyzer (SEM-EDXA Unit, Main Defense Chemical Laboratory). For the scanning electron microscopic examination, the collected teeth were examined at $30 \mathrm{kV}$ using the secondary electron LFD detector under the magnification (X 1000), (x2000) and (X4000) with a (spot size 4.7e5.5 nm) in each magnification. Surface (Ca) and (P) weight \% were measured with energy dispersive X-ray analysis (EDXA) with S-UTW detector (EDXA Inc., Mahwah, NJ, USA). The count rate of the EDXA detector was between 1800 and 2000 counts per second with a resolution of $132.14 \mathrm{eV}$ (Rabertson and Nietzche 2009). Statistical analysis was used for data management and analysis so paired T-test was used to compare the values before and after immersion in different products, one way analysis of variance (ANOVA) followed by Tukey type non-parametric post hoc test are used for multiple comparisons, to determine differences between groups and $\mathrm{Ca}$ and $\mathrm{P}$ contents.

\section{Results:-}

Histological results

Control groups (before bleaching)

SEM examination of all control groups presented more or less the same surface features of enamel with few variations from one specimen to another. The enamel surface features were presented as perikymata grooves with observable enamel rod ends, areas of rodless enamel, areas of eroded enamel and few scratches of different depths were seen in some specimens (Fig 1).

\section{Experimental group (after bleaching procedure)}

The teeth of the control group utilized as experimental after application of bleaching materials as follows:

\section{Experimental group I (EGI)}

Scanning electron micrographs for the same parts of enamel that were scanned as control after exposure to in office bleaching and artificial saliva showed dissolution of the enamel surface, surface erosion, depressions of various depth, craters and some porosity. Loss of the prismatic layer. Few precipitates were observed. Enamel surface with many exposed enamel prisms (Fig 2).

\section{Experimental group II (EGII)}

Scanning electron micrographs for the same parts of enamel that were scanned as control after exposure to at home bleaching and artificial saliva showed mild dissolution of some enamel superficial areas and areas of rodless enamel with more accentuated scratches. Increase of surface irregularities, loss of interrod areas and continuity of the irregular rods spaces. A higher magnification showing few precipitates at the boundaries of enamel rod ends (Fig 3). 


\section{Experimental group III (EGIII)}

Scanning electron micrographs for the same parts of enamel that were scanned as control after exposure to in office bleaching, ACP and artificial saliva showed that perikymata grooves became shallower than that in control group \& ridges were less conspicuous. Craters were observed and surrounded by some precipitates. Some precipitates were observed on the entire examined surface and at the boundaries of enamel rod ends. A higher magnification presented apparently shallower surface scratches than in CGIII. Occlusion of enamel rod ends was detected.

\section{Experimental group IV (EGIV)}

Scanning electron micrographs for the same parts of enamel that were scanned as control after exposure to at home bleaching, ACP and artificial saliva showed that perikymata grooves became shallower than that in control group \& ridges were less conspicuous. Craters were observed and surrounded by some precipitates. Some precipitates were observed on the entire examined surface and at the boundaries of enamel rod ends. A higher magnification presented occlusion of enamel rod ends.

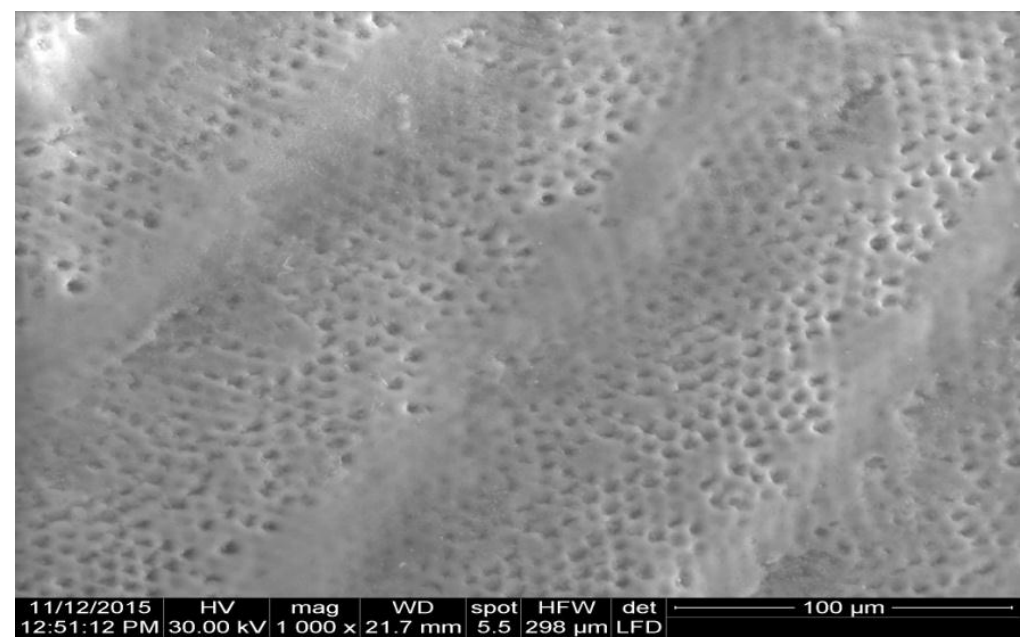

Fig 1:-A scanning electron micrograph for the middle third of the buccal enamel of the CGI group showing perikymata groove (PG) with enamel rod ends (blue arrow), and areas of rodless enamel (RLE) (X 1000).

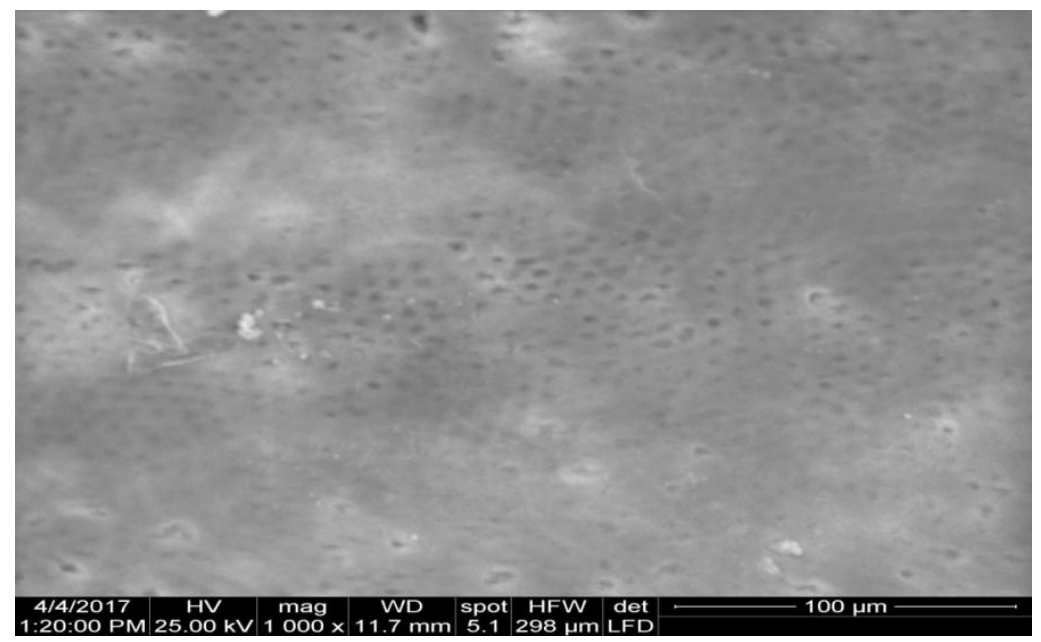

Fig 2:-A scanning electron micrograph for enamel of EGI group (the same part that was scanned as a control in Fig.2) showing loss of the prismatic layer, craters and areas of eroded enamel. Perikymata grooves become apparently shallower (X 1000). 


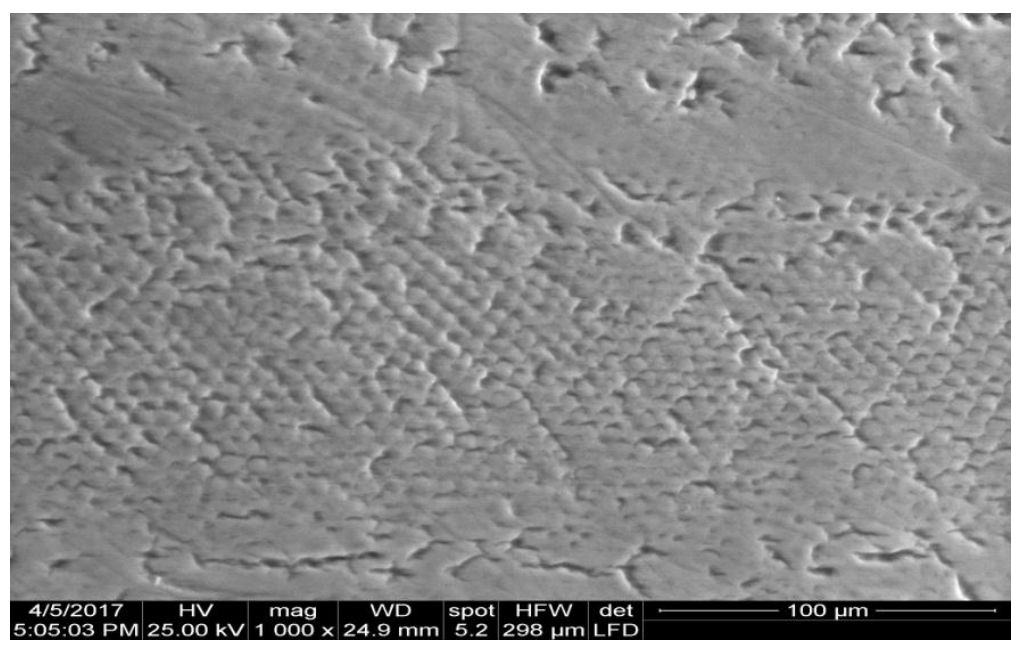

Fig 3:-A scanning electron micrograph for enamel of EGII group (the same part that was scanned as a control in Fig.6) showing mild intraprismatic dissolution of some enamel superficial areas and areas of rodless enamel with more accentuated scratches (X 1000).

\section{Statistical Results:-}

From the statistical analysis, it was noticed that there were highly significance differences between the four different bleaching scenarios regarding the changes in the mean surface $\mathrm{Ca}, \mathrm{P}$, and $\mathrm{C}$ weight percent at the middle third of the enamel surface after immersion. Mean percent of Ca was decreased in the EG I and EG II groups by $1.84 \%$ and $0.18 \%$, respectively. While, in EG III and EG IV it was increased by $0.18 \%$ and $1.70 \%$, respectively. Meanwhile, the mean percent of surface $\mathrm{P}$ weight, at the middle third of the enamel surface, decreased in both EG I and EG II by $1.18 \%$ and $0.22 \%$, respectively. But, in EG III and EG IV increased mean percent of surface P weight by $0.16 \%$ and $1.70 \%$, respectively. On contrast, the mean percent in surface $\mathrm{C}$ weight percent, at the middle third of the enamel surface, increase in EG I and EG II by $1.71 \%$ and $0.12 \%$, respectively. But, it was decreased in EG III and EG IV groups by $0.12 \%$ and $1.27 \%$, respectively, see Fig. 32 .

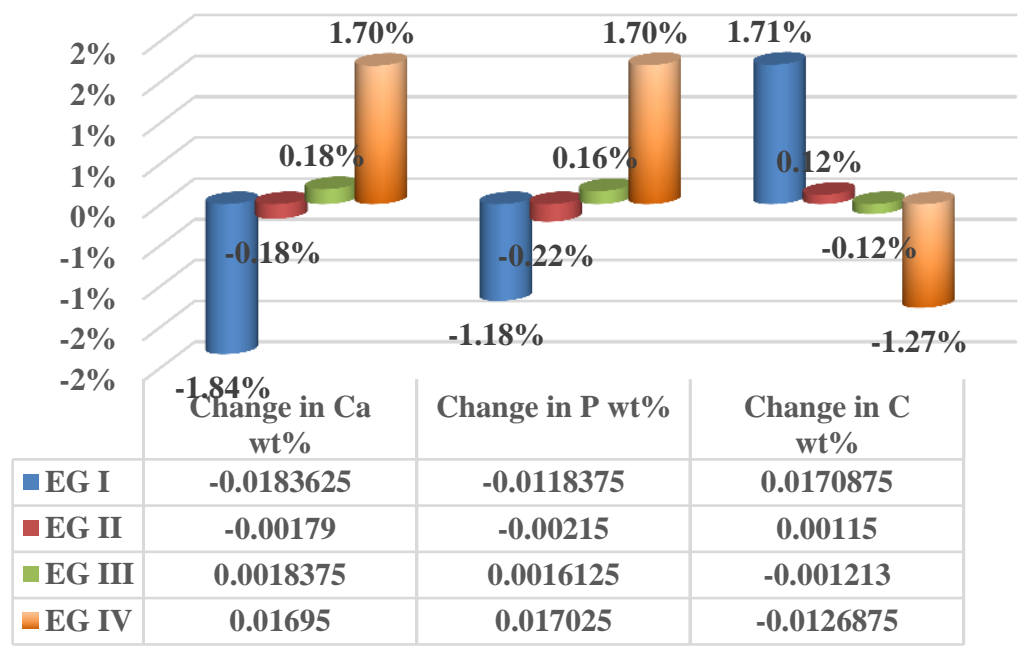

Fig 3.2:-Bar chart representing loss/gain relationship in mean $\%$ of surfaceCa, $\mathrm{P}$, and $\mathrm{C}$ weight percent at the middle third of the enamel surface after bleaching.

\section{Ternary Diagram for the Four Experimental Groups:}

As can be seen in the ternary diagram of the four experimental groups, shown in Fig.37, EG I group has the lowest Ca and $\mathrm{P}$ wt $\%$ and the highest $\mathrm{C}$ wt $\%$ (worst treatment). On contrary, EG IV has the highest $\mathrm{Ca}$ and $\mathrm{P}$ wt $\%$ and the lowest $\mathrm{C}$ wt\% (best treatment). While, EG II and EG III have intermediate wt\% values between EG I and EG IV. 


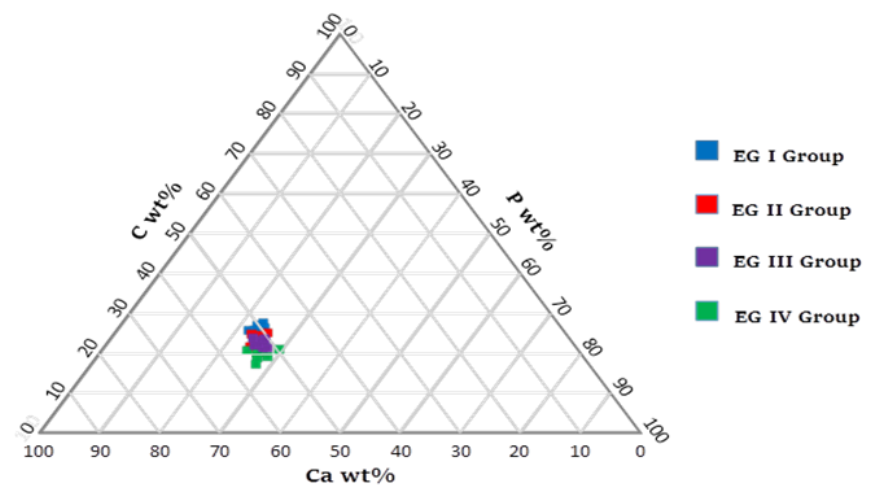

Fig 3.7:-Ternary diagram showing the relationship between $\mathrm{Ca}, \mathrm{P}$ and $\mathrm{C}$ wt $\%$ of the enamel surface in EG I, EG II, EGIII and EG IV groups.

\section{Discussion:-}

Tooth bleaching is one of the most conservative dental treatments to improve or enhance a person's smile. However, tooth bleaching is not risk-free and only limited long-term clinical data are available on the side

effects of tooth bleaching.

Improvement of teeth appearance is one of the most goals of esthetic dentistry. This is achieved by a wide range of bleaching agents. The commonly used bleaching techniques are in office bleaching and at home bleaching. Vital tooth bleaching is associated with many side effects, which include enamel surface alterations and tooth sensitivity, which can be reduced with re-mineralizing agents. The presence of saliva, fluorides or other re-mineralizing agents is to maintain the balance between the remineralization and demineralization processes. This study aimed to compare the effect of hydrogen peroxide (in-office bleaching) and carbamide peroxide (home bleaching) on human surface enamel and the effect of amorphous calcium phosphate (ACP) as a re-mineralizing agent following bleaching (Haywood, 2000; Hemagaran and Neelakantan, 2014).

The sample in this study was an intact enamel of sound teeth as it makes the study more realistic for assessing the effect of the bleaching material and ACP components and predicting their possible clinical behavior. Other studies have been done on powdered enamel to provide us with information about changes in molecular structures of teeth (Dogan et al, 2005). Although powdered enamel provides a satisfactory screening method, the changes induced are generally magnified because of the high surface area exposed and absence of organic matrix.

The use of intact enamel of sound human premolars in this study would help in predicting the possible influence of different bleaching agents and ACP. However, many researchers have preferred to use bovine teeth since it is considered as an alternative for human teeth since they can be easily obtained (Zero, 1996) but there are structural differences between bovine and human enamel. Bovine enamel is more porous than human enamel. Accordingly, it is less resistant to acid diffusion (Meurman et al., 1996).

Due to the irreversible damage to hard dental tissues, clinical judgments based on case reports, rather than clinical trials, are required to identify the etiological factors that cause dental lesions as erosion. Carrying out clinical trials to investigate these etiological factors would have neither therapeutic nor preventive values and would damage their dental health irreversibly. Therefore, these studies would not be only counterproductive but also be considered by the review board to be an abuse of human teeth.The middle one third of the buccal surface was used in this study as a monitoring area for the buccal surface of enamel as it consists of a moderate percentage of the elements between incisal and cervical enamel. This is based on the research work of (Takahahi et al, 2008), who studied the difference in the incisal and cervical enamel elemental composition of the human permanent teeth by using electron probe micro-analyzer that quantitively analyzed the contents of several elements (calcium, phosphorous, oxygen, carbon, magnesium, sodium and 
fluorine). Their results revealed that the cervical enamel calcification level was lower than that at the cuspal enamel as the $\mathrm{Ca}$ and $\mathrm{P}$ weight percent was less in the cervical enamel.

In the current study, artificial saliva was used as a storage medium to simulate the intr-oral environment. The presence of artificial saliva and use of ACP to induce mineral saturation in the tooth structure were important to reduce demineralization process and increase remineralization process of tooth structures. In many studies, artificial saliva acts as a suitable medium for possible remineralization of dental enamel. It can regain the mineral loss or increase disrupted surface microhardness (Attin et al, 2000; and Meyer et al, 2004)

In this study, the use of EDAX-analysis conducted on the SEM was used for detecting the presence and relative quantities of elements in the teeth. This is supported by (Willershausen and Schulz-Dobrich, 2004). It is the most suitable technique for examining elemental composition within localized small areas of mineralized enamel structure. The main advantage of EDAX is its capability to analyze in situ weigh percentages on the order of a few cubic microns in a nondestructive way and to correlate the distribution of different elements to the tissue histological structure (Samuel and Rubinstein, 2001).

In this study, the percentage of $\mathrm{Na}$ and $\mathrm{F}$ contents were below the limit of detection for EDAX, so the concern was the change in the weight percentage of the three elements $\mathrm{Ca}, \mathrm{P}$ and $\mathrm{C}$ in relation to each other. Amitava et al, 2010 reported that enamel apatite is one unit of carbonated hydroxyapatite that contains several elements, but $\mathrm{Ca}, \mathrm{P}$ and carbonate in addition to $\mathrm{Na}$ and $\mathrm{F}$ are the elements which have diversity in relation to mineralization.

In the present study, the in-office bleaching (EGI) (40\% hydrogen peroxide without remineralizingagent) effect on the morphology of enamel surface converted into defective eroded surface with depressions of various depth, craters and some porosity. Enamel rod ends are irregular and widely opened. This was in accordance with a study done by using two applications of $35 \%$ hydrogen peroxide, which was light-activated with halogen lamp and remained in contact with enamel for 20min with total exposure time 40min (Miranda et al, 2005). Cakir et al, 2012 reported that the use of office bleaching agents (38\% hydrogen peroxide) could affect the chemical composition of enamel and dentin.

Cadenaro et al, (2010) reported that the use hydrogen peroxide bleaching agents with high concentration caused structural and morphological alteration of the enamel surface, including increased porosity, demineralization and a decrease in the concentration of protein, degradation of organic matrix, $\mathrm{Ca} / \mathrm{P}$ ratio modification and $\mathrm{Ca}$ loss.

The current study showed that after application of in office bleaching material, there was a significant increase in $\mathrm{C} w \mathrm{wt}$ correlated to a significant decrease in P content. It is supposed that carbon may replace $\mathrm{OH}$ or $\mathrm{P}$ in the apatite lattice. The increase in carbon means a decrease in the hardness of enamel (Amitava et al, 2010) and this reflects the increase of enamel solubility resulting in an erosive effect. The $\mathrm{Ca}$ content decreased that confirmed the release of $\mathrm{Ca}$ from enamel surface due to the destruction of the surface hydroxyapatite. This is compatible with Pinto et al, 2004 who revealed that peroxide bleaching agent reduced the microhardness of enamel. Lopes et al., 2002 reported that the higher concentration of hydrogen peroxide in Opalescence Boost ${ }^{\circledR}$ and the absence of urea in its composition are the main cause to keep the $\mathrm{pH}$ close to the critical level for enamel demineralization and thus, it reduces microhardness.

In our study, few precipitates were observed may be due to immersion into artificial saliva for 48 hours (baseline). Saliva can regain some of the mineral loss caused by bleaching process and the reduction in microhardness may be compensated by remineralization following bleaching process and any microstructural defects may be repaired by the absorption and precipitation of the salivary components present in artificial saliva (Alves et al., 2007)

On the other hand, in this study, the SEM examination of EGII group indicated the demineralizing effect of at home bleaching (35\% carbamide peroxide without remineralizing agent) on enamel surface. Mild dissolution of some enamel superficial areas was produced with surface irregularities. This was in accordance with a study done by applying Opalescence Quick 35\% CP (according to the manufacturer's instructions) on human enamel (Pinto et al, 2004). Sulieman A, (2008) showed areas of shallow erosions and significant changes in enamel bleached with carbamide peroxide.

These results in agreement with Awliya et al, (2006) and Cavalli et al, (2004) who found that urea resulted from breakdown of carbamide peroxide, penetrate enamel resulting in destructive effects. Urea adversely affected the interprismatic substance and increased surface permeability. Therefore, it can promote structural and morphological 
changes in enamel and dentin. However, urea could promote beneficial effects due to its alkaline nature which raise the bleaching agent $\mathrm{pH}$ and reduce the demineralization potential.

This was confirmed also by the ternary diagram of CG II and EG II groups that showed a very slight shift towards the increase in the $\mathrm{C}$ wt $\%$ and a decrease in both the $\mathrm{Ca}$ and $\mathrm{P}$ wt \%.

Lopes et al, (2002) contradicted the morphological results as they found no adverse effects on enamel microhardness or on surface morphology following bleaching with 10\% carbamide peroxide. Also, Do Amaral et al, (2012) revealed that home-use and in-office bleaching gels did not alter the concentrations of calcium and phosphorus on the enamel surface in vivo. The divergences in the results of different studies might be due to differing study designs, including different dental samples (bovine or human teeth); differences in storage conditions (distilled water, artificial saliva, or human saliva); fluoride use or lack thereof; the type of the study (in vitro vs. in vivo); concentration and composition of the bleaching agent; $\mathrm{pH}$ of the bleaching agent (acidic or neutral) and the duration of each treatment session.

On the other hand, these irregularities are difficult to be considered as secondary effects of the treatment. When the enamel surfaces were examined in the control groups, shallow depressions, pores and superficial irregularities are detected. Perikymata, circumferentially horizontal lines may be found across the buccal aspect of the crown; on the other side, cracks and lamellae are not unusual. Enamel surface varies with age as shown by SEM.

In the current study, following application of in-office bleaching agent and ACP (EGIII), it was noticeable thatperikymata grooves became shallower, some precipitates on the examined surface and occlusion of enamel rod ends were detected. This is accordance with (Klaric et al, 2013)

whoevaluated the effects of in-office bleaching agents with high concentration of hydrogen peroxide on human enamel and dentin surface. The results showed significant increase in surface microhardness and closed dentinal tubule by mineral deposition following application of ACP gel with artificial saliva storage of bleached enamel surfaces. This is in parallel with Oliveira et al, (2005) who revealed that incorporating ACP into the bleaching agent might not be able to avoid demineralization but they might inhibit the progression of demineralization process.

The ternary diagram showed a very slight shift between CG III group and EG III towards the increase in both the Ca and $\mathrm{P}$ weight $\%$ and a decrease in the $\mathrm{C}$ weight $\%$. These results might be due to the remineralization capacity of ACP and artificial saliva. This is in accordance with Reynold et al, (2003) who mentioned that the localization of ACP at the tooth surface buffers the free calcium and phosphate ion activities, thus helping to maintain a state of supersaturation which depresses demineralization and enhances remineralization of the enamel.

Under the conditions of this study, the SEM of EGIV (35\% CP and ACP) showed amorphous, globular or spherical precipitates more than in EGIII (40\% HP and ACP). This can be explained by the presence of urea ( a breakdown of carbamide peroxide) in EGIV which can penetrate enamel affecting the interprismatic substance and increasing surface permeability. Therefore, it may facilitate the penetration of ACP resulting in more precipitates in EGIV than in EGIII that have no urea. urea resulted from breakdown of carbamide peroxide, penetrate enamel resulting in destructive effects (Cavalli et al, 2004).

In our study, the ternary diagram showed rather the most pronounced shift between CG IV and EG IV towards the increase in both the $\mathrm{Ca}$ and $\mathrm{P}$ wt $\%$ and a decrease in the $\mathrm{C}$ wt \%. This is in parallel with de Vasconceloset al (2012) who reported that combination of peroxides with CPP-ACP showed increased hardness, roughness and mineral deposition. In vivo conditions, enamel pellicle and saliva protect tooth surface, so the demineralized enamel and dentin following bleaching can undergo recalcification. In in vitro conditions, ACP post-treatment provides calcium and phosphate ions that can decrease surface roughness and enhance remineralization of enamel and dentin.

Finally, in vitro studies do not provide enough results of remineralization that might take place in the tooth structure exposed to human saliva. However, few in situ studies have been carried out to show the direct interaction among bleaching agents, saliva, soft tissues and dental structures. But further evaluations should be accomplished.

\section{Conclusion: -}

This in vitro investigation showed that:

The exposure to chemical activated $40 \%$ hydrogen peroxide (in-office) significantly altered enamel surface morphology. 
The exposure to chemical activated 35\% carbamide peroxide (at home) resulted in mild changes in surface morphology of enamel.

In-office and at-home bleaching affected the calcium and phosphorous levels of teeth.

Saliva as a reservoir of calcium and phosphate ions cannot prevent irreversible structural changes.

Relief ACP post bleaching agent showed a significant increase in calcium and phosphorous levels as well as surface morphological alterations.

Treatment with ACP led to improved surface roughness, and enhanced remineralization of the hard dental tissues. ACP is effective on repairing enamel surface morphology.

The use of the protective agents can be useful clinically to reduce negative changes of enamel surface after whitening procedures and repair enamel surface morphology.

\section{References:-}

1. Attin T, Weiss K, Becker K, Buchalla W and Wiegand A: Impact of modified acidic soft drinks on enamel erosion. Oral Dis; 11(1):7-12, 2005.

2. Sturdevant CM, Roberson TM, Heymann HO and Sturdevant JR: The art and science of operative dentistry. 5th. Philadelphia: Mosby; pp. 640-6, 2006.

3. Watts A and Addy M: Tooth discoloration and staining: a review of the literature. Br Dent J 190:309-315, 2001.

4. Sulieman AMM. An overview of tooth-bleaching techniques: chemistry, safety and efficacy. Periodontol 2000;48: 148- 169, 2008.

5. Dietschi D, Benbachir N and Krejci I: In vitro colorimetric evaluation of the efficacy of home bleaching and overthe-counter bleaching products. Quintessence Int; 41:505-16, 2010 .

6. Kim YS, Kwon HK and Kim BI: Effect of nano-carbonate apatite to prevent re-stain after dental bleaching in vitro. J Dent 39:636-42, 2011.

7. Maryline M and Rene S: Vital tooth bleaching-biologic adverse effects- a review. QuintenPubl 39:645-59, 2008.

8. Olta U and Gurgan S: Effects of three concentrations of carbamide peroxide on the structure of enamel. J Oral Rehabil 27:332-340, 2000.

9. Moraes RR, Marimon JL, Schneider LF, CorrerSobrinho L ,Camacho GB and Bueno M: Carbamide peroxide bleaching agents effect on surface roughness of enamel, composite and porcelain. Clin Oral Investg 10:23-28, 2006.

10. Budavari S, Oneil MJ, Smith A and Heckelman PE: The Merck index. An encyclopedia of chemicals, drugs, and biological. Rahway, NJ: Merck and Co.,Inc., 1989.

11. Sun G: The role of lasers in cosmetic dentistry. Dent. Clin. North Am.44:831-850, 2000.

12. Archambault G: Caution, informed consent remain important as home bleaching grows. Dentist; 68: 16-22, 1990 .

13. Boskey AL: Amorphous calcium phosphate: the contention of bone. J Dent Res.; 76:1433-1436,1997 .

14.Eanes ED, Gillessen IH and Posner AS: Intermediate states in the precipitation of hydroxyapatite Nature; 208:365367, 1965.

15. Arnold WH and Gaengler P: Light and electron microscope study of infilteration of resin into initial caries lesions-a new methodological approach. Journal of Microscopy; 245:26-33, 2012.

16. Sathe N, ChakradharRaju RVS and Chandrasekhar V: Effect of Three Different Remineralizing Agents on Enamel Caries Formation - An in vitro Study. Kathmandu university medical journal, 12(1):16-20, 2014.

17.Horning D, Gomes GM, Bittencourt BF, Ruiz LM, Reis A and Gomes OMM: Evaluation of human enamel permeability exposed to bleaching agents. Braz J Oral Sci, 12(2):114-118, 2013.

18. Rabertson A. and Nietzche S: Histology and x-ray microanalysis of reparative dentin in primary teeth. $\mathrm{J}$ of microscopy and analysis; 190:13-18, 2009.

19. Meurman JH and Ten Cate JM. Pathogenesis and modifying factors of dental erosion. Eur J Oral Sci; 104:199-206, 1996.

20.Takahashi M, Goto S, Mori k and Mataga I: Difference of histology and elemental composition of the cervical enamel among human permanent teeth. Frontier of Material Science in China, 2(4):437-440, 2008.

21. Attin T, Bu Chall A W, Gollner M and Hellwig E: Use of variable remineralization periods to improve the abrasion resistance of previously eroded enamel. Caries Res; 34:48-52, 2000. 
22. Meyer -Lueckel H, Umland N, Hopeen-Muller W and KielbAssa AM. Effect of mucin alone and in combination with various dentifrices on in vitro remineralization. Caries Res ;38:478-83, 2004.

23. Willershausen B and Schulz-Dobrick B: In vitro study on dental erosion provoked by various beverages using electron probe microanalysis, European Journal of Medical Research; 29:432-438, 2004.

24. Samuel S and Rubeinstein C: Microhardness of enamel restored with fluoride and non-flouride releasing dental materials. Brazilian Dental Journal ; 12:35-38, 2001.

25. Amitava M, Elisa B, Silivia M and Lia R: Biomimetics Learning from Nature. In: Dental tissue engineering: a new approach to dental tissue reconstruction, InTech, 2010.

26. Miranda CB, Pagani C, Benetti AR and Matuda FS: Evaluation of the bleached human enamel by scanning electron microscopy. J ApplSci 13(2)204-11, 2005.

27. Cakir FY, Oztas SS, Firat E and Gurgan S: Effect of office bleaching systems on chemical compositions of enamel and dentin: an in vitro study. Clinical Dentistry And Research.36(3):35-41, 2012.

28. Cadenaro M, Navarra CO, Mazzoni A, Nucci C, Matis BA and Di Lenarda R et al. An in vivo study of the effect of a 38 percent hydrogen peroxide in-office whitening agent on enamel. J Am Dent Assoc ; 141: 449-454, 2010.

29.Pinto C F, Oliveira R, Cavalli V and Giannini M: Peroxide bleaching agent effects on enamel surface microhardness, roughness and morphology. Braz Oral Res 18(4): 306-11, 2004.

30.Lopes G.C, Bonissoni L., Baratieri L.N, Viera L.C, and Monteiro S.: Effect of bleaching agents on the hardness and morphology of enamel Journal of Esthetic and Restorative Dentistry (14): 24-29, 2002.

31. Alves E.A, Aves F.K, Compos E.D. and Mathias P.: Susceptibility to caries like lesions after dental bleaching with different techniques, quimetessence international; (38): 404-409, 2007.

32. Sulieman AMM. An overview of tooth-bleaching techniques: chemistry, safety and efficacy. Periodontol 2000;48: 148- 169, 2008.

33. Awliya YM, Al-Jaralla A and Abdul Qader A: Alteration in enamel morphology after using six bleaching products. A scanning electron microscope study. Saudi dental journal; 18(1), 2006.

34. Cavalli V, Arrais AG, Gianini M, and Ambrosano GMB: High-concentrated carbamide peroxide bleaching agents effects on enamel surface. Journal of Oral Rehabilitation; 32:155-159, 2004.

35. Do Amaral FLB, Sasaki RT, Da Silva TCR, Franca FMG, Florio FM and Basting RT: The effect of home-use and inoffice bleaching treatments on calcium and phosphorus concentrations in tooth enamel: an in vivo study. JADA; 143(6):580-586, 2012.

36. Klarić E, Marcius M, Ristić M, Sever I, Prskalo K and Tarle Z: Surface changes of enamel and dentin after two different bleaching procedures. ActaClin Croat 52(4):420-429, 2013.

37. Oliveria R, Paesleme AF and Giannini M: Effect of a carbamide bleaching gel containing calcium or fluoride on human enamel surface hardness. Brazilian Dental Journal,2, 2005.

38. Reynolds EC, Cai F, Shen P andWalker GD: Retention in plaque and remineralization of enamel lesions by various forms of calcium in a mouthrinse or sugar-free chewing gum. Journal of Dental Research 82:206-11, 2003 .

39. De Vasconcelos AA, Cunh AAG and Borges BC: Enamel properties after tooth bleaching with hydrogen/carbamide peroxides in association with a CPP-ACP paste. ActaOdontolScand; 70:337-43, 2012.

40. Haywood VB: Current status of nigthguard vital bleaching. Compendium of Continuing Education of Dentistry; 28:S10-17; quiz S48, 2000.

41. Hemagaran G and Neelakantan P: Remineralization of the tooth structure. International Journal of PhamTech Research; 6(2):487-493,2014. 